\title{
CFD Analysis on Pumps Working as Turbines
}

Himanshu Nautiyal, Varun and Anoop Kumar
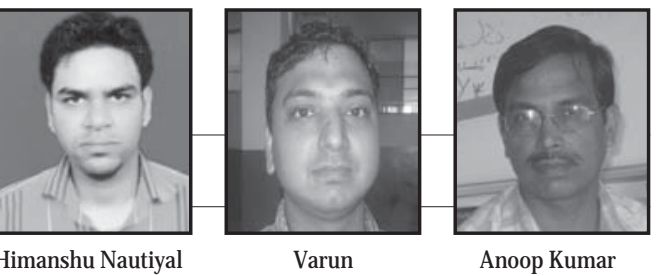

Abstract: Reverse running centrifugal pumps are an effective source of reducing the equipment cost in small hydropower plants. The manufacturers do not provide any information on the performance and flow characteristics when pumps are operated in turbine mode. Lack of Pump as Turbine (PAT) performance data is a significant barrier to the wider use of PAT. Application of Computational Fluid Dynamics (CFD) is a recent attempt for predicting the performance of PAT. CFD analysis is an effective design tool for predicting the performance of reverse running operation of centrifugal pumps. But some deviations still exist in experimental and CFD results of reverse operation of pumps. Future works in the field of computational analysis can further improve the prediction of pumps in reverse operation.

Key words: Pump as Turbine (PAT), Computational Fluid Dynamics (CFD), pump

$\mathrm{D}_{\mathrm{t}}^{\mathrm{N}}$ ue to the current energy crises, the necessity of finding alternatives to conventional sources for energy generation has increased. Among the alternatives small hydropower is one of the most promising and significant. Small hydropower schemes are in demand throughout the world because they can be established even in situations of small water resources. But the problem of high initial capital cost is associated with the installation of small hydropower schemes in water streams commonly found in remote and rural areas, like forests and alpine areas. The remote areas are commonly found in developing countries that are facing the problems of electricity crises.

The use of centrifugal pumps in reverse direction is an effective way to reduce the equipment cost in small hydropower schemes. Take the case of reconstruction of the Dobromyslyansk Small Hydroelectric Station on the Chernitsa River, in the Minsk District of Belarus, eastern Europe (Berlin 1993). In the Dobromyslyansk station, the problem arose due to the unavailability of small turbines and generators of 100-150 kW capacity and a head of four to six meters. The proposed turbine Pr20/811-V-100 was rejected due to the high cost and absence of proper time delivery. The problem of equipping the station was solved by the use of pumps as turbines (PAT) and induction motors as generators for electricity generation. Consequently, the Dobromyslyansk small hydroelectric station became the first such station with PAT to be installed within the Commonwealth of Independent States.

Theuse of PAT isalso a promisingsolution to theproblem of rural electrification in other countries. For example, PAT projects are working to provide electricity to rural areas in Tanzania at Kinko (10 kW) (Singh et al 2006); in Kenya at Thima (2.2 kW) (Maher, Smith and Williams 2003); and in northern Thailand at Huai Kra Thingvillage (Greacen 2006). Apart from power production, pumps in reverse operation can also be used in energy recovery systems, water supply systems, etc. Pumps are mass produced, available in various sizes and have the advantages of low cost and simplicity.

The idea of power generation by reverse running pumps
wasstartedaround1930(Chapallaz,EichenbergerandFischer 1992). Studies of using PAT demonstrate some important consequences. Pumps are relatively simple machines and easily available in all developed and developing countries. PAT has acceptable efficiency for fixed flow operations. Some difficulties still exist, however, in the application of pumps for power production, given their limited efficiency, low part load efficiency, and poor regulation capabilities. Also, pump manufacturers do not have information on the performance and flow characteristics when pumps are operated in turbine mode. Lack of PAT performance data is a significant barrier to the wider use of PAT (Greacen 2006, Tamm et al 2000, and Williams 1995). Furthermore, a main challenge in electricity generation through pumps is the proper selection of PAT for a specific site.

Considerable theoretical, experimental and computational research has been done in the area of reverse operation of a pump. An extensive growth in thearea of Computational Fluid Analysis (CFD) has been seen over the last few decades. This technology has been widely used in various engineering areas such as aviation, fluid mechanics and oceanography. CFD helps predict fluid flow by means of mathematical modeling, software tools and numerical methods.

Theflowinanyturbo-machineisalwaysthreedimensional (3-D) and unsteady. A better knowledge of flow inside the turbo-machines is essential for improving the results. A greater understanding of the complex flow patterns inside the turbo-machines can be possible with computational analysis. The interaction between impeller and volute in pumps can be well predicted by using numerical methods. CFX-5.6, Pro-Engineer, Fluent, FineTurbo, and BladeGen are some important software for numerical analysis of turbo-machines. In CFD analysis, the solution convergence depends on the mesh quality. Some parts of turbo machines have complex geometry which leads to difficulty in obtaining a better mesh quality of such geometries while some parts are generally simple in construction, so, good mesh quality can beeasily obtained. Application of CFD is a recentattempt for predicting the performance of PAT. The application of 
CFD and its limitations for PAT are presented.

In CFD analysis, simplifications have to be done for analyzing the machines, simplifications in the geometry induced error in the results. In centrifugal pumps, the effect of geometric simplification is greater in turbine mode. The effect on downstream flow is greater than upstream flow. Derakhshan and Nourbakhsh (2008) compared CFD and experimental results of pump working in turbine mode for a low specific speed centrifugal pump.A3-D model of the pump is shown in Figure 1. The whole impeller and the volute were present in the model for complete computational study of pump operations. CFD results supported the experimental data are available in pump mode, but in turbine mode CFD and experimental results have not been matched within acceptable limits. Similar discharge, head and power values obtained by CFD were lower than the experimental values. The real geometry and CFD model were different in interaction between volute and impeller, because flow zone in space between hub/ shroud and casing was not included in the model (Figure 2).

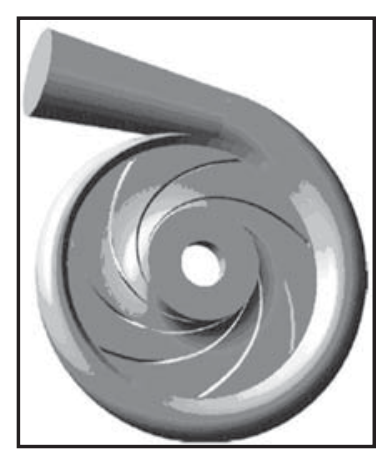

Figure 13-D Model of Simulate Pump by Derakhshan and Nourbakhsh (2008)

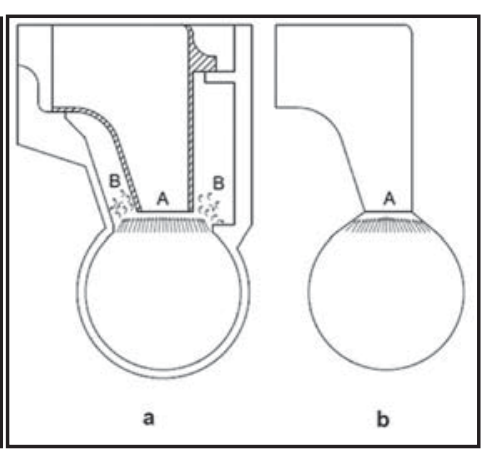

Figure 2 Interaction Between Volute and Impeller (a) Real Geometry, (b) CFD Model (Derakhshan and Nourbakhsh 2008).
Natanasabapathi and Kshirsagar (2004) predicted the flow through a PAT for which experimental results are available. The CFD analysis of the pump was done using CFX-5.6 software. The numerical values of head drop were matching with the experimental values, but there was deviation in the efficiency calculated from CFD at discharges away from BEP as shown in Figure 3a. To eliminate the deviations, two rings of structured grid were then introduced in between casing and runner and the results were improved as shown in Figure 3b. This shows that unrealistic results can be obtained from unstructured griding across the interface between stationary and rotating frame of reference. Structured griding near the interface is a solution to minimize such unrealistic results.

An investigation was carried out by Rodrigues et al (2003) by using the concept of 'flow zone' analysis to the computational study of PAT performance. The complex flow regime within a PAT was divided into four major flow regions (viz., casing volute, impeller, casing outlet and draft

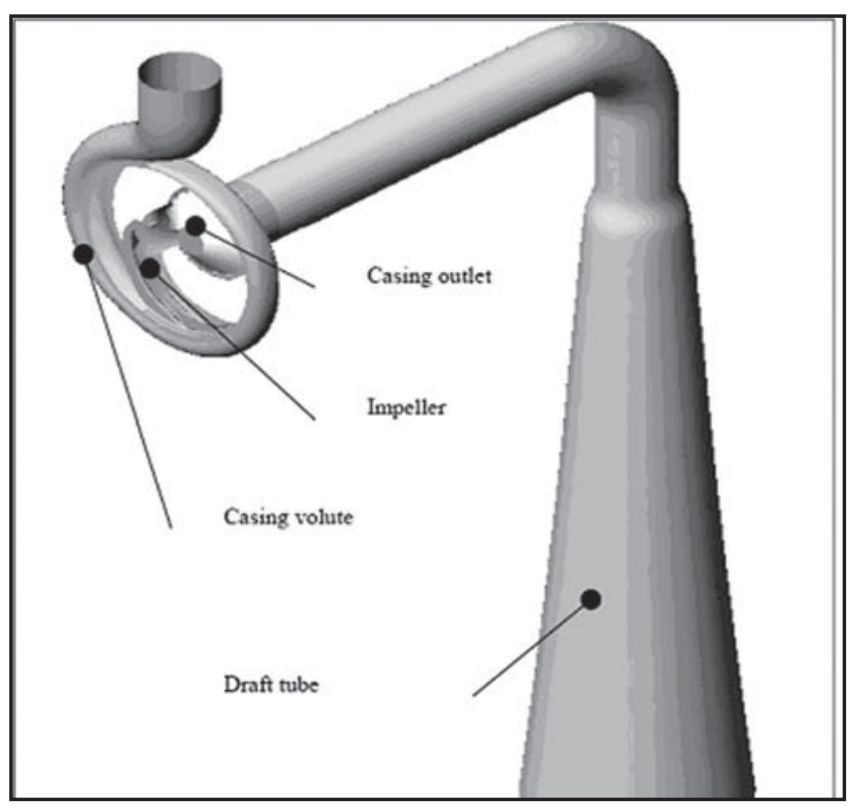

Figure 4 Domains in Centrifugal Pump (Rodrigues et al 2003)

tube for CFD analysis) as shown in Figure 4. Comparison was done between experimental and numerical results of a single stage end suction centrifugal pump (NW8 Kirloskar) operating as turbine at a speed of $800 \mathrm{rpm}$. Although CFD predictions of the hydraulic parameters compare well with experimental results, some deviations within 5\% to $10 \%$ appeared (excluding no load regions).

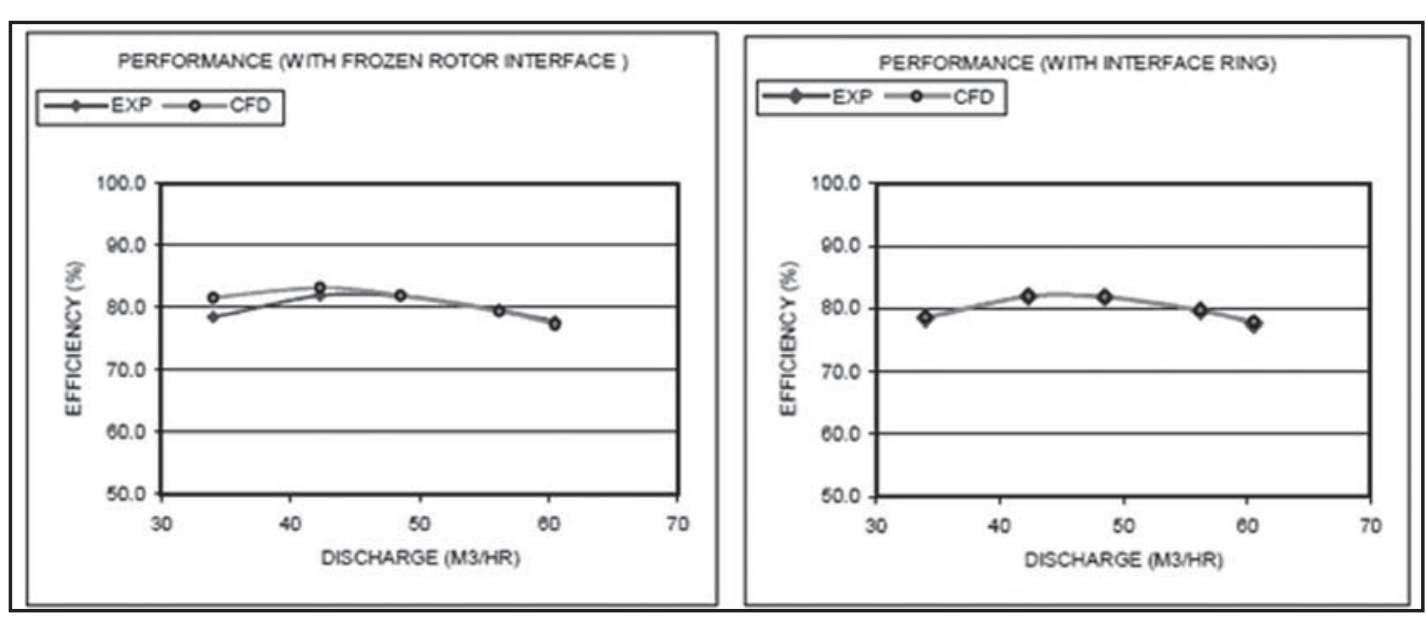

Figure 3a Comparison Without Interface Ring

Two methods (viz., forceintegration method and hydraulic loss method) have been used to determine torque in $\mathrm{CFD}$ analysis. A high torque is shown in the no load and part load regions by the hydraulic loss approach. The hydraulic loss 


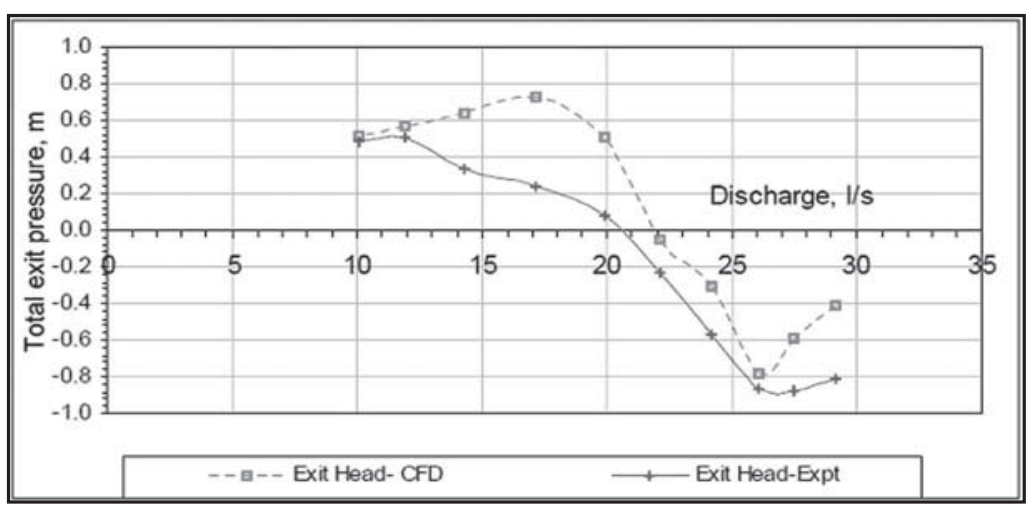

Figure 5. Comparison of CFD and Experimental Results for Total Exit Pressure (Rodrigues et al 2003)

as a Lecturer in Department of Mechanical Engineering atNIT, Hamirpur, India. Hisareas of interest are solar air heater, life cycle assessment and heat transfer. He has published more than 23 papers in national and international journals. Corresponding address: varun7go@gmail.com

Anoop Kumar, $\mathrm{PhD}$, is presently working as Professor and Head of the Department of Mechanical Engineering at NIT, Hamirpur, India. His areas of interest are CFD and heat transfer. He has more than 20 years of teaching experience.

approach gives better information of the internal flow in a PAT and has been used in all subsequent analysis. Comparison between predicted and experimentallydetermined hydraulic losses showed encouraging results. Numerical results were matched with the experimental results except part load zones. This shows the limitation of the CFD model when PAT is operating away from the design conditions. Nonetheless, the overall prediction of hydraulic losses was acceptable.

The comparison between CFD and experimental total exit pressures predicted that CFD results wereslightly higher than the experimental results (Figure 5). The representation of draft tube in coarse grid pattern may be one of the reasons for the inaccurate results in CFD analysis.

The above cases show that CFD analysis is an effective design tool for predicting the performance of reverse running operation of centrifugal pumps. The computational analysis is very useful in identifying the losses in turbomachine components like draft tube, impeller, casing. In the above cases, the CFD and experimental results do not match accurately in turbine operation of pumps, but the difference can be minimized through improvement in computational analysis by using finer mesh, numerical methods and turbulences models. More experience in computational analysis will also help to obtain accurate convergence of CFD results with experimental data. Future works in the field of computational analysis can further improve the prediction of pumps in reverse operation.

Himanshu Nautiyal graduated in Mechanical Engineering in 2008 and is pursuing an M. Tech degree from NIT (National Institute of Technology, Hamirpur, Himachal Pradesh, India) in Thermal specialization with CFD and Heat Transfer. His areas of interest are turbomachinery and non-conventional energy sources. Corresponding address: h2nautiyal@gmail.com

Varun graduated in Mechanical Engineering in 2002 followed by his M. Tech degree in Alternate Hydro Energy Systems in 2004 from IIT (Indian Institute of Technology, Roorkee, Uttarakhand, India). He is presently working
Corresponding address: jas.anoop@gmail.com

\section{References}

Berlin, V.V. and O.A. Murav'ev, 1993, Puttinginto operation the first small hydroelectric station with pumps and motors as turbines and generators in the Commonwealth of Independent States, Hydrotechnical construction v.27, n.9.

Chapallaz, J.M., P. Eichenberger and G. Fischer, 1992, Manual on Pumps Used as Turbines, Braunschweig, Germany: Vieweg.

Derakhshan S. and A. Nourbakhsh, 2008, Theoretical, numerical and experimental investigation of centrifugal pumps in reverse operation, Experimental Thermal and Fluid Science v.32, pp.1620-27.

Greacen, C, 2006, Project Report: Huai Kra Thing MicroHydro Project, Border Green Energy, Thailand; URL: www. bget.org.

Maher P, N.P.A. Smith and A.A. Williams, 2003, Assessment of pico hydro as an option for off-grid electrification in Kenya, Journal of Renewable Energy v.28, pp.1357-69.

Natanasabapathi, S.R. and J.T. Kshirsagar, 2004, Pump as Turbine: An Experience with CFX-5.6, Pune, India: Kirloskar Bros. Ltd., Corporate Research and Engineering Division.

Rodrigues A., P. Singh, A. Williams, F. Nestmann and E. Lai, 2003, Hydraulic analysis of a pump as a turbine with CFD and experimental data, a paper presented at the IMechE Seminar on Computational Fluid Dynamics for Fluid Machinery, London, 18th November.

Singh, P., V. Ramasubramanian, A. Rao and A.K. Kumar, 2006, Performance evaluation of the pump as turbine based micro hydro project in Kinko village, Tanzania, a paper presented at the Himalayan Small Hydropower Summit, Dehradun, India, October 12-13.

Tamm A., A. Braten, B. Stoffel and G. Ludwig, 2000, Analysis of a standard pump in reverse operation using CFD, paper number PD-05 presented at the 20th IAHRSymposium, Charlotte, North Carolina USA.

Williams, A., 1995, Pumps as Turbines Users Guide, London: International Technology Publications. • 